\title{
Effect of Pressure and Preheating Temperature on Droplet Measure of Waste Cooking Oil
}

\author{
I K.G. Wirawan $^{* 1}$, Ainul Ghurri ${ }^{* 2}$, W. N. Septiadi ${ }^{* 3}$ \\ *Department of Mechanical Engineering, Faculty of Engineering \\ Udayana University Bali, Indonesia \\ 1ikgwirawan@unud.ac.id \\ 2a.ghurri@gmail.com \\ ${ }^{3}$ wayan.nata@gmail.com
}

\begin{abstract}
Palm oil is usually used for cooking. The usage of this oil is frequently associated with health issues, especially if it consumed repeatedly. In fact, waste cooking oil (WCO) can be used as fuel and safe for the environment. The aim of this research is to know the characteristics of the droplets size. WCO is given preheating and pressure treatment before a simple nozzle exits. The experiment begins by inserting WCO into a tube through the intake. Air compressor is inserted into the tube and pressure level is maintained at 3 bar. The valve is opened slowly so that WCO flows through the pipe line to the spiral pre-heater. Pre-heater temperature is varied at $350,360,370,380$ and $390^{\circ} \mathrm{C}$. Afterwards, WCO flows into the main body of nozzle. Spray particle of WCO on the nozzle are captured using the camera. The same experiment was repeated using pressure at 4 and 5 bar. Result of droplet size was obtained by fluctuation at pressure 3 and 4 bar. When pressure was raised 5 bar, the droplets size decreases.
\end{abstract}

Keywords : waste cooking oil, preheating, pressure, droplets size

\section{INTRODUCTION}

Palm oil is commonly used for household needs and if it used repeatedly, it would decrease human health. It needs a proper handling, so this waste cooking oil (WCO) can be used as fuel and doesn't pollute the environment.

There are two ways to utilize waste cooking oil (WCO) as fuel. The first way would be carried out by performing some processes into the WCO until it became biodiesel, through purification using a catalyst within esterification[1],[2],[3] and transesterification [4],[5],6]. These biodiesel can be used for fuel, both in internal or external combustion. However, the process took a relatively long time because there are stages of deposition, filtration, and washing, so that the time required would be longer and surely there was an additional cost for the catalyst. In other words, biodiesel would not be efficient if produced on a small scale. The second way is to use it directly as an external combustion fuel. This way is relatively practical because it does not require a complicated process. The only process that needs to be done is just filtering, so WCO would be free from dirt. This way of utilization could be done on small scale.

WCO has flash point and viscosity respectively $309^{\circ} \mathrm{C}$ and $124 \mathrm{cSt}$ [7], greater than kerosene $38^{\circ} \mathrm{C}$ and 1.6cSt [8]. Due to its properties, WCO couldn't be used as fuel directly. Initial preheating is needed to be done on WCO to solve this issue so its viscosity and density could be decreased. A good droplet size will be generated if the injection pressure is increased [9].

This research aims to determine the characteristics of distribution of droplets size, related to WCO on the nozzle. WCO would be applied on the pressure stove as an alternative fuel [10].

\section{MATERIAL AND METHOD}

The materials used for waste cooking oil (WCO) were taken from hotels and restaurant in Bali. WCO was collected by Lengis Hijau Foundation. Testing of oil composition was conducted at Integrated Testing and Research Laboratory, Gadjah Mada University, as shown in Table 1. 
TABLE 1. The Contents of Waste Cooking Oil

\begin{tabular}{|c|l|c|}
\hline No & \multicolumn{1}{|c|}{ Content } & Percentage (\%) \\
\hline 1 & Methyl Laurate & 0.24 \\
\hline 2 & Methyl Tetradecanoate & 0.89 \\
\hline 3 & Methyl Palmitate & 0.61 \\
\hline 4 & Methyl Palmitoleate & 34.84 \\
\hline 5 & Cis-10-Heptadecenoic Methyl Ester & 0.57 \\
\hline 6 & Lenolelaidic Acid Methyl Ester & 56.31 \\
\hline 7 & Methyl Lenoleate & 4.34 \\
\hline 8 & Methyl Aracehidate & 0.77 \\
\hline 9 & Gamma-lenolenic Acid Methyl Ester & 0.15 \\
\hline 10 & Methyl Cis-11-eicocenoate & 0.31 \\
\hline 11 & Cis-11-14-eicosadienoic Acid Methyl Ester & 0.34 \\
\hline 12 & Methyl Docosanoate & 0.43 \\
\hline 13 & Methyl Cis-5-8-11-14-17- Eicosapentaenoate & 0.09 \\
\hline 14 & Other & 0.11 \\
\hline
\end{tabular}

Experiment begins by putting waste cooking oil (WCO) into a tube through fuel intake. Pressurized air enters the tube using a compressor and its pressure level was maintained 3 bar as shown in Figure 1 . The valve was opened slowly so that pressurized WCO flowed through pipe line to spiral-spotted pre-heater. Pre-heater temperature was varied from $350,360,370,380$, until $390^{\circ} \mathrm{C}$. Then, WCO flows into main body nozzle. Spray injection that happened in nozzle was captured using camera. Same experiment was carried out again by pressure 4 and 5 bar.

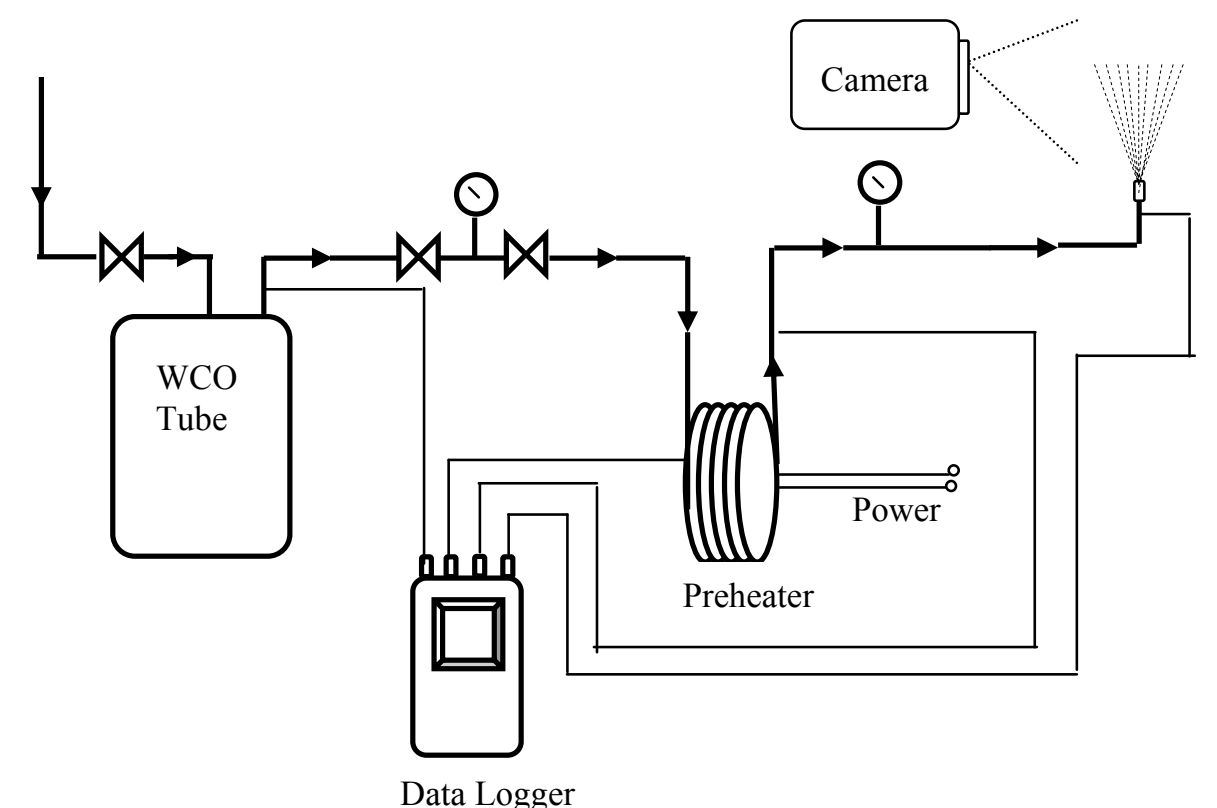

$$
\begin{aligned}
& \text { : Pressure Gauge } \\
& \text { - : Valve }
\end{aligned}
$$

Fig.1. Experiment set up 


\section{RESULTS AND DISCUSSION}

WCO has long chain of fatty acid and susceptible to oxidation, so it would increase viscosity and change its physical and chemical properties [11]. In order to decrease the viscosity, preheating was applied on the spiral copper pipe flowed by WCO. When pre-heater was increased then WCO viscosity was decreased. WCO is given the pressure of causing the fluid is converted into a thin sheet that formed ligament which subsequently break into droplets spray.

The Image $\mathrm{J}$ software was used for analyzing the photo of spray droplets, as shown in Figure 2, 3, and 4. The next process was analyzed the particles to obtain maximum and minimum size of droplets, as illustrated in Table 2.

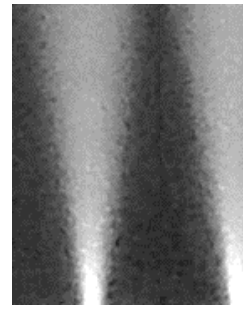

(a)

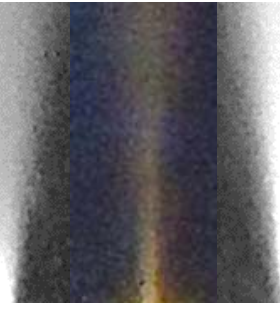

(b) (c)

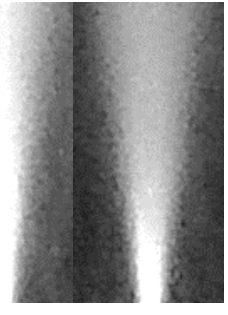

(d)

(e)

Fig. 2. Pressure 3 bar and preheating temperature, (a) $350{ }^{\circ} \mathrm{C}$, (b) $360{ }^{\circ} \mathrm{C}$, (c) $370,{ }^{\circ} \mathrm{C}$ (d) $380{ }^{\circ} \mathrm{C}$, (e) $390^{\circ} \mathrm{C}$

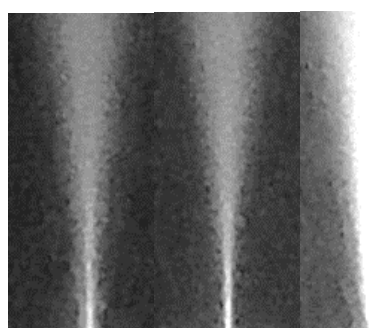

(a) (b)

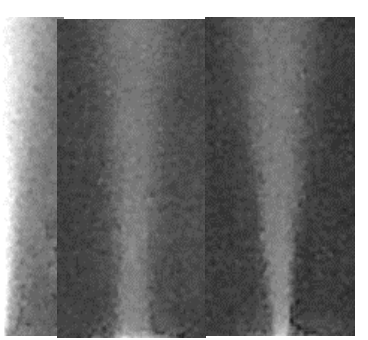

(d)

(e)

Fig. 3. Pressure 4 bar and preheating temperature, (a) $350^{\circ} \mathrm{C}$, (b) $360{ }^{\circ} \mathrm{C}$, (c) $370,{ }^{\circ} \mathrm{C}$ (d) $380{ }^{\circ} \mathrm{C}$, (e) $390^{\circ} \mathrm{C}$

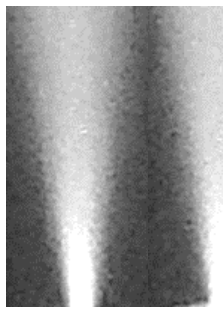

(a)

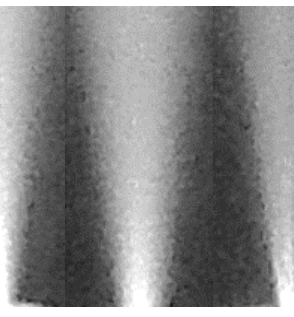

(b) (c)

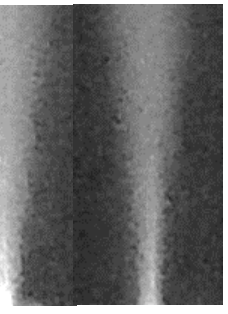

(d)

(e)

Fig. 4. Pressure 5 bar and preheating temperature, (a) $350{ }^{\circ} \mathrm{C}$, (b) $360{ }^{\circ} \mathrm{C}$, (c) $370,{ }^{\circ} \mathrm{C}$ (d) $380{ }^{\circ} \mathrm{C}$, (e) $390^{\circ} \mathrm{C}$ 
TABLE 2. Droplets Size in Variations of Pressure and Temperature

\begin{tabular}{|c|c|c|c|}
\hline \multirow{3}{*}{ Pressure (bar) } & $\begin{array}{c}\text { Preheating } \\
\text { temperature }\left({ }^{\circ} \mathrm{C}\right)\end{array}$ & \multicolumn{2}{|c|}{ Droplet size $(\mu \mathrm{m})$} \\
\cline { 2 - 4 } & 350 & 7 & Max \\
\cline { 2 - 4 } & 360 & 10 & 186 \\
\cline { 2 - 4 } & 370 & 10 & 211 \\
\cline { 2 - 4 } & 380 & 17 & 246 \\
\cline { 2 - 4 } & 390 & 9 & 216 \\
\hline \multirow{4}{*}{4} & 350 & 9 & 160 \\
\cline { 2 - 4 } & 360 & 11 & 169 \\
\cline { 2 - 4 } & 370 & 12 & 242 \\
\cline { 2 - 4 } & 380 & 10 & 135 \\
\hline \multirow{4}{*}{5} & 390 & 15 & 213 \\
\cline { 2 - 4 } & 350 & 8 & 226 \\
\cline { 2 - 4 } & 360 & 4 & 169 \\
\cline { 2 - 4 } & 370 & 14 & 191 \\
\hline & 380 & 10 & 133 \\
\hline
\end{tabular}

The results of data processing is presented by graphic that is the maximum and minimum droplet size in variation of temperature and pressure, as illustrated in Figure 5, 6, and 7.

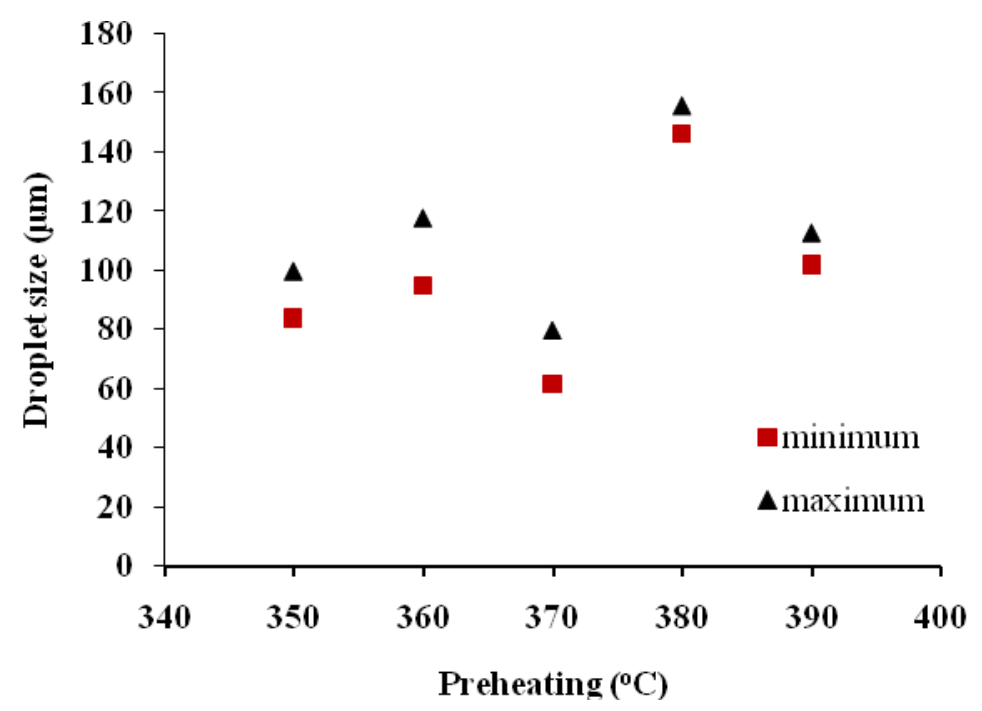

Fig. 5. Relation of preheating temperature and droplets size at 3 bar 


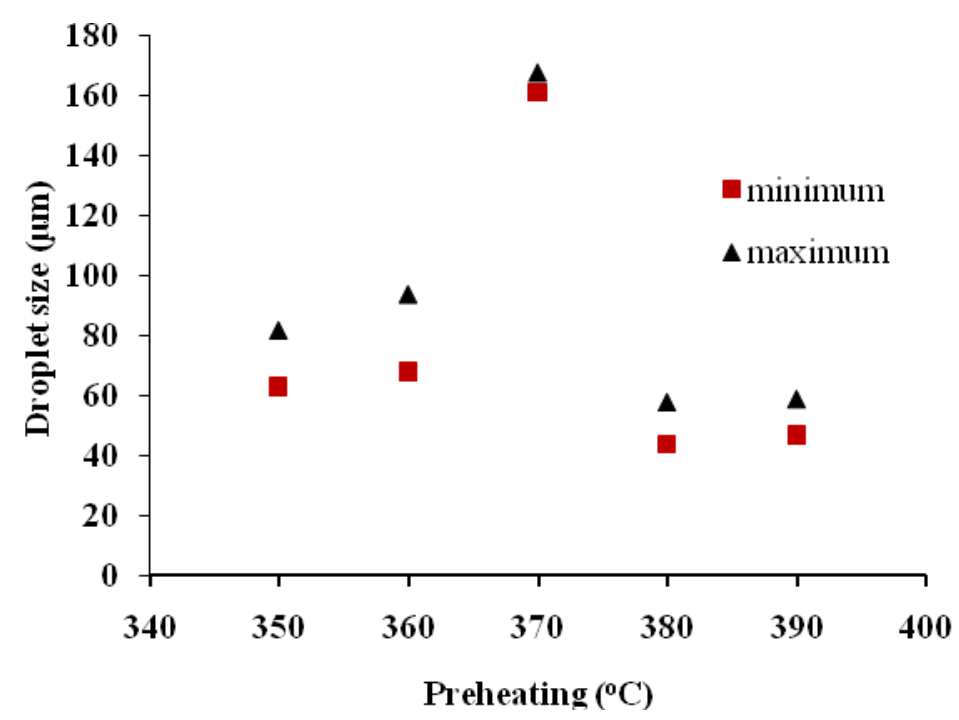

Fig. 6. Relation of preheating temperature and droplet size at 4 bar

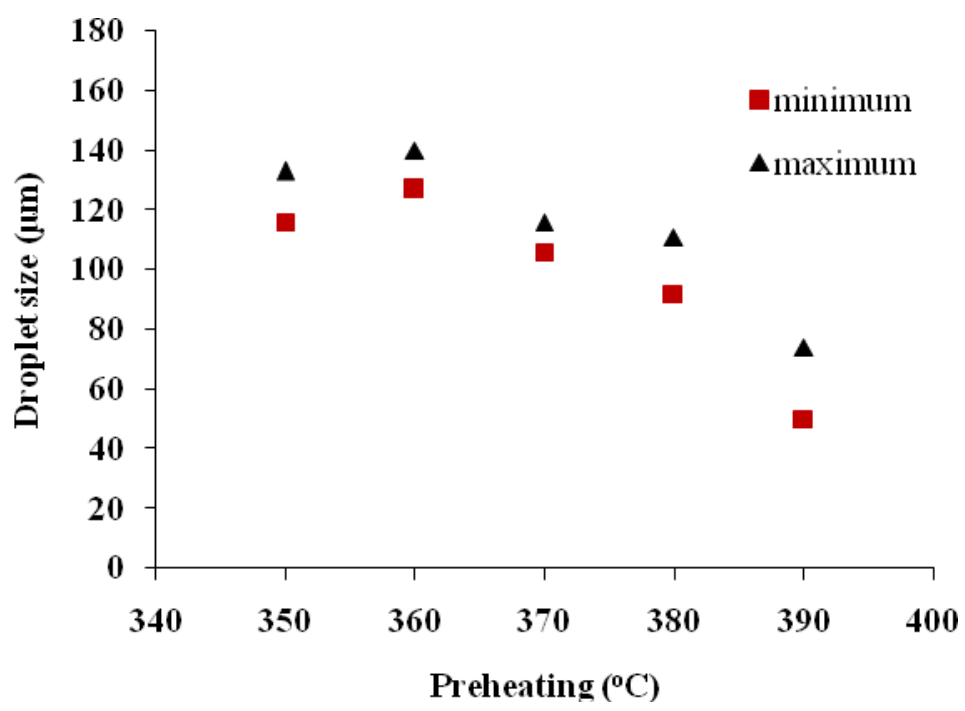

Figure 7 Relation of preheating temperature and droplet size at 5 bar

Free fatty acid (FFA) content of WCO increases in the temperature range from 350 to $390^{\circ} \mathrm{C}$ due to hydrolysis process. FFA will become fluid flow impurities. The droplet size becomes fluctuating at pressures of 3 and 4 bar because the deposit of FFA is formed in the nozzle [12]. When the pressure was raised 5 bar, the droplet size tends to decreases.

\section{CONCLUSION}

Increased both pressure and temperature produce fluctuating droplet size, because the deposit started to form on the nozzle due to free fatty acid. When pressure was increased to $5 \mathrm{bar}$, the size of droplet was decreased. The maximum size of droplet is $246 \mu \mathrm{m}$ and the minimum size of droplet is $4 \mu \mathrm{m}$.

\section{ACKNOWLEDGEMENTS}

This research is supported by The General Directorate of Research and Higher Education (RISTEKDIKTI) with contract Number: 415.64/ UN14.4.A/ PL/ 2017 via Institute for Research and Community Services (LPPM), Udayana University Bali, Indonesia. The gratitude is also given to Yoga Junaya from Mechanical Engineering Department, Udayana University. 


\section{REFERENCES}

[1] João Felipe G. Oliveira, Izabelly Larissa Lucena, Rosana M. Alves Saboya, Marcelo L. Rodrigues, Antonio Eurico B.Torres, Fabiano A. Narciso Fernandes, Célio L. Cavalcante Jr., Expedito José S. Parente Jr., Biodiesel Production from Waste Coconut Oil by Esterification with Ethanol: The Effect of Water Removal by Adsorption, Renewable Energy 35 (2010) 2581-2584.

[2] M.L. Pisarello, B. Dalla Costa, G. Mendow, C.A. Querini, Esterification with Ethanol to Produce Biodiesel from High Acidity Raw Materials Kinetic Studies and Analysis of Secondary Reactions, Fuel Processing Technology 91 (2010) 1005-1014.

[3] Thi Tuong Vi Tran, Sunanta Kaiprommarat, Suwadee Kongparakul, Prasert Reubroycharoen, Guoqing Guan, Manh Huan Nguyen, Chanatip Samart, Green Biodiesel Production From Waste Cooking Oil Using an Environmentally Benign Acid Catalyst, Waste Management 52 (2016) 367-374.

[4] Chaudhry Haider Ali, Abdul Sattar Qureshi, Serge Maurice Mbadinga, Jin-Feng Liu, Shi-Zhong Yang, Bo-Zhong Mu, Biodiese Production from Waste Cooking Oil Using Onsite Produced Purified Lipase from Pseudomonas Aeruginosa FW_SH-1: Central Composite Design Approach, Renewable Energy 109 (2017) 93-100.

[5] H. Amani, Z. Ahmad, M. Asif, B.H. Hameed, Transesterification of Waste Cooking Palm Oil by MnZr with Supported Alumina as a Potential Heterogeneous Catalyst, Journal of Industrial and Engineering Chemistry 20 (2014) 4437- 4442.

[6] Thawatchai Maneerung, Sibudjing Kawi, Yanjun Dai, Chi-Hwa Wang, Sustainable Biodiesel Production Via Transesterification of Waste Cooking Oil by Using CaO Catalysts Prepared from Chicken Manure, Energy Conversion and Management 123 (2016) 487497.

[7] Lai Fatt Chuah, Suzana Yusup, Abdul Rashid Abd Aziz, Awais Bokhari, Mohd Zamri Abdullah, Cleaner Production of Methyl Ester Using Waste Cooking Oil Derived from Palm Olein Using a Hydrodynamic Cavitation Reactor, Journal of Cleaner Production 112 (2016) $4505-4514$.

[8] Puneet Verma, M.P. Sharma, Gaurav Dwivedi, Evaluation and Enhancement of Cold Flow Properties of Palm Oil and Its Biodiesel, Energy Reports 2 (2016) 8-13.

[9] M.R. Aliff Radzuan, M.A. Abia Biteo Belope, R.B. Thorpe, Removal of fine Oil Droplets from Oil-in-Water Mixtures by Dissolved Air flotation, Chemical engineering research and design115(2016) 19-33.

[10] Ashok Yadav, Prakash Chandra Jha, A Case Study on Biofuel Stove Technology: Jatropha as a Biofuel, International Journal of Technology Enhancements And Emerging Engineering Research, Vol 1, Issue 2 (2013) 14-18.

[11] Syed Aatif Avase, Shivank Srivastava, Kumar Vishal, Harsh V Ashok, George Varghese, Effect of Pyrogallol as an Antioxidant on the Performance and Emission Characteristics of Biodiesel Derived from Waste Cooking Oil, Procedia Earth and Planetary Science 11 ( 2015 ) 437-444,

[12] Kratzeisen M. and Müller J., 2010. Influence of Free Fatty Acid Content of Coconut Oil on Deposit and Performance of Plant Oil Pressure Stoves, Fuel 89: 1583-1589.

\section{AUTHOR PROFILE}

I Ketut Gede Wirawan was born on Denpasar in Indonesia. An engineer degree was obtained in Mechanical Engineering Brawijaya University (Indonesia), Master degree from Institute of Sepuluh Nopember Surabaya (Indonesia) and Pursuing degree of Doctoral in Mechanical Engineering Brawijaya University Indonesia. He is working as lecturer in the Depatement of Mechanical Engineering Udayana University Indonesia. His interest field is renewable energy.

Ainul Ghurri was born on Blitar in Indonesia. An engineer degree was obtained in Mechanical Engineering Brawijaya University (Indonesia), Master degree from Indonesia University, Pursuing Ph.D from Chonbuk National University South Korea. He is working as lecturer in the Depatement of Mechanical Engineering Udayana University Indonesia. His interest field is internal combustion engine.

Wayan Nata Septiadi was born on Klungkung in Indonesia. An engineer degree was obtained in Mechanical Engineering Udayana University (Indonesia). Master and Doctoral degree from Indonesia University. He is working as lecturer in the Depatement of Mechanical Engineering Udayana University Indonesia. His interest field is nano fluid. 